\title{
ANIMACIÓN DE OBJETOS Y DE FORMAS EN LOS CINEÍSTAS MURCIANOS. INFLUENCIAS DE LA ANIMACIÓN INTERNACIONAL EN EL CINE AMATEUR
}

\section{OBJECTS AND FORMS ANIMATION IN MURCIAN CINEÍSTAS. INTERNATIONAL ANIMATION INFLUENCES IN AMATEUR CINEMA}

\author{
Carlos Salas González \\ Universidad de Murcia
}

\section{RESUMEN}

El movimiento de cine amateur que surgió en Murcia en los años cincuenta constituye uno de los elementos más destacables en la cultura y el arte de dicha ciudad en la última centuria. Con una extensa y variada producción de cortometrajes, Murcia pasó a ser el segundo foco nacional, tras Barcelona, en lo referente a este tipo de creaciones. El objetivo de este estudio es poner en valor el notable papel que en dicha producción representaron los filmes de animación, en concreto los de animación de objetos y de formas abstractas, así como evidenciar la importante influencia que en ellos tuvieron los principales realizadores de este tipo de animación a nivel internacional.

Palabras clave: cine, Murcia, animación, stop motion, cineista

\section{ABSTRACT}

The amateur film movement which emerged in Murcia in the fifties is one of the most outstanding elements in the culture and art of the city in the last century. With a wide and varied production of short films, Murcia became the second national focus in this kind of creations, being Barcelona the leader. The goals of this study are valuing the remarkable role of animation films in the mentioned production, specifically those animating objects and abstract forms, as well as evidencing the important influence that the main international directors of this type of animation had on them.

Keywords: cinema, Murcia, animation, stop motion, cineista 


\section{INTRODUCCIÓN}

Corría la década de los cincuenta cuando el emblemático Café Santos se convirtió en el epicentro de la vida intelectual, cultural y artística de la ciudad de Murcia. Fueron varias las tertulias que a lo largo de los años -hasta que cerrase definitivamente sus puertas en los ochenta-tuvieron lugar entre sus paredes, resultando la más nutrida, variopinta y fértil aquella de la que vino a nacer, allá por 1954, la asociación Amigos de la Fotografía y del Cine Amateur (AFCA), casa común de los cineístas murcianos. $\mathrm{Y}$ es que fue así como decidieron llamarse quienes, desde inicios de aquella década, se atrevieron a hacer cine en este extremo del sureste español, siguiendo el ejemplo de sus colegas y predecesores barceloneses ${ }^{1}$. Ninguno de sus miembros era profesional en el ámbito audiovisual, desempeñando cada cual profesiones de lo más diverso. Comerciantes, docentes, periodistas o médicos, entre otros profesionales, tuvieron el arrojo de adentrarse en aquella aventura que era la realización de películas en la tardía posguerra.

Julián Oñate, Antonio Medina y Pedro Sanz, miembros permanentes de la tertulia del Santos, fueron quienes, junto a Antonio Crespo, sembraron la simiente de la mencionada asociación y, en definitiva, de lo que sería ese extenso y diverso grupo de los cineastas amateurs. Llegaron a editar una revista, Encuadre, de la que se publicaron quince números entre octubre de 1956 y mayo de $1958^{2}$. Además de una intensa y dilatada amistad, les unían una vasta cultura y una notable pasión por el cine. La falta de medios técnicos y económicos era otro notable nexo de unión, pero dicha carencia se compensaba con altas dosis de ingenio y entusiasmo. Eran cinéfilos, pretendiendo estar al tanto de cuantas novedades y hallazgos acontecían en el séptimo arte. De ahí que, sumando ambos factores -la falta de recursos materiales y la puesta al día en las últimas tendencias cinematográficas-, podamos encontrar como resultado de sus proyectos y trabajos unos filmes con un marcado carácter autoral, en ocasiones abiertamente experimentales, y en todos los casos al margen de la industria.

Emplearon todo tipo de formatos no profesionales, desde el 9'5 mm hasta el Super-8, pasando por los más habituales en los años de máxima producción y mayor esplendor desde mediados de los cincuenta hasta inicios de los setenta- que fueron el $8 \mathrm{~mm}$ y el 16 $\mathrm{mm}$. La fotografía en blanco y negro prevaleció en las primeras realizaciones, pasando a ser mayoritarias las de color desde finales de la década de los cincuenta. En la mayoría de los casos eran películas sin diálogos, en las que el acompañamiento musical generalmente desempeñaba un papel de notable importancia, siendo también muy diversos los estilos empleados, desde la música clásica hasta el pop. Su duración solía estar comprendida en los parámetros propios del cortometraje. Los géneros y temas fueron de una gran variedad, utilizándose tres categorías para clasificarlas: documental -fueron especialmente relevantes por su calidad e interés las de carácter etnográfico y muy abundantes las de viajes-, argumento -bajo esta etiqueta la variedad fue enorme, pasando por el drama, la comedia o el terror- y fantasía ${ }^{3}$, término que englobaba tanto trabajos de animación - prevalecieron los realizados con la técnica del stop motion-- como otros que presentaban diversos tipos de experimentación formal, narrativa o estética. Todo ello hizo que Murcia se situase, tras Barcelona, como el más importante núcleo de cine amateur en la España de los cincuenta y sesenta ${ }^{4}$.

Por lo anteriormente expuesto resulta fácil hacerse a la idea de la muy notable variedad, tanto de forma como de contenido, de la que gozó aquel cine, de la misma manera que por los gustos, intereses y propósitos de sus creadores nos podemos imaginar el decisivo papel referencial que las vanguardias fílmicas y los movimientos cinematográficos más en boga en aquellas décadas llegaron a tener en él. En algunos de sus trabajos más notables destaca la huella del neorrealismo italiano - Una aventura vulgar (Antonio Crespo, 1953), Caridad (Pedro Sanz, 1955), El limpia (Pedro Sanz, 1956)...-, la de los nuevos cines europeos-Primer día de caza (Antonio Medina, 1958)- o la del surrealismo y otros movimientos herederos -Psiquis (Antonio

1 Este tipo de cine encontró a menudo el desprecio o, en ocasiones, directamente el rechazo de la crítica. Véase, a modo de ejemplo, lo que en una revista de arte y literatura catalana opinaba uno de sus colaboradores acerca del movimiento del cine amateur: Felíu, 1957a:14-15.

2 De dicha revista se realizó una edición facsímil en dos volúmenes. Véase Cerón, 2003a; 2003b.

3 En un principio a este tipo de películas se les denominó de vanguardia, atendiendo a las categorías que establecía el Certamen Nacional de Barcelona, pero pronto el término empleado por los cineístas murcianos sería el de fantasía. Véase Cánovas y Cerón, 1990: 26.

4 Resulta significativo cómo los cineastas murcianos presumían de esta condición con apenas tres años de andadura. Véase la noticia recogida en su propia revista: Murcia ocupa el segundo puesto en el cine amateur español. Encuadre, 1, $1956:$ 6-7. 
Medina, 1961)-. Pero entre ellos tuvieron una especial relevancia los filmes de animación. Y no precisamente los de dibujos animados, por lo general destinados a un público infantil, sino los realizados a partir de la animación de objetos -este efecto se consigue captando la imagen fotograma a fotograma, técnica para la que hoy se ha generalizado el uso de la expresión anglosajona stop motion- y los de animación de formas abstractas, no argumentales, y que se suelen englobar bajo el concepto de animación experimental. Es a estas obras a las que dedicamos este breve estudio. Para ello analizaremos las más emblemáticas de cuantas fueron realizadas en la época de eclosión y esplendor del cine amateur murciano, la que va desde su origen -el año 1953, fecha en que Antonio Crespo realizó Una aventura vulgar ${ }^{5}$ - hasta la década de los setenta, momento en el que los cineistas y su asociación quedaron definitivamente integrados en la Caja de Ahorros del Sureste y su recién creada Cátedra de Cinematografía.

\section{ANIMACIÓN DE OBJETOS}

Como ya se ha dicho con anterioridad, dentro de la categoría de fantasía los cineístas murcianos realizaron un buen número de películas de animación. Entre ellas destacaron las de animación de objetos, llevadas a cabo a partir del stop motion o paso de manivela ${ }^{6}$. Dicha técnica se había empleado desde tiempos muy tempranos, existiendo notables ejemplos en algunas destacadas películas de la primera década del XX. Un pionero de la animación como el norteamericano Stuart Blackton la había empleado en algunos de sus filmes, caso de Humorous Phases of Funny Faces (Fases humoristicas de caras divertidas, 1906) o The Haunted Hotel (El hotel encantado, 1907), como también lo hizo el español Segundo de Chomón, experto en trucajes que trabajaba en París para la Pathé, en algunas de sus realizaciones más sobresalientes: La maison ensorcelée (La casa embrujada, 1907), Hôtel électrique (El hotel eléctrico, 1908) o Une excursion incoherente (Una excursión incoherente, 1909), entre otras. Y solo unos pocos años más tarde, el ruso Wladyslaw Starewicz la utilizaría para hacer películas enteras protagonizadas por personajes -en sus primeros filmes se trataba de insectoscompletamente animados según esta técnica, siendo Mest Kinomatograficheskovo Operatora (La venganza del camarógrafo, 1912) la primera y más famosa de ellas.

Medio siglo después, en Murcia, los cineastas amateurs se atrevieron con esta técnica, que resultaba tan convincente como trabajosa. En este sentido, tuvieron como referentes más directos algunos trabajos de destacados cineistas catalanes como Juan Llobet, Fermín Marimón, Felipe Sagués o José Mestres. El primer caso de un filme completo empleándola lo encontramos en Póker (1957), de Julián Oñate, resultando una de las películas más notables y premiadas de cuantas realizaron los cineistas murcianos. Se trataba, sencillamente, de una partida de cartas con baraja francesa, pero en la que los naipes se movían solos, sin que en la película apareciese persona alguna. Entre los premios recibidos habría que destacar los logrados en el XIX Certamen UNICA y el XX Concurso Nacional de Barcelona ${ }^{7}$. Lamentablemente, la película hoy se ha perdido, conservándose solo unos cuantos planos. Aquel mismo año, Pedro Sanz también se decidió a utilizar esta técnica, aunque parcialmente, en Cosas de toros. Se trata de un cortometraje de particular carácter documental sobre la tauromaquia. La parte de objetos animados está protagonizada por las figuras de un torero y de un toro, ambas juguetes. El mismo realizador insistiría en dicha técnica tan solo un año después con la película Julieta y Romeo, historia protagonizada por dos huevos y teniendo como escenario una modesta cocina. Sanz contó con la ayuda de Oñate como operador, así como del carrocista y dibujante Antonio González Conte, quien fue el encargado de dibujar los cambiantes y expresivos rostros de los huevos.

También el prolífico Antonio Medina había experimentado con la técnica del stop motion durante aquellos años, destacando su película La noche (1957). En ella, unos sencillos

5 Es cierto que Julián Oñate había filmado Canuto, ladrón astuto en 1952, es decir, un año antes de que Crespo realizase su laureada ópera prima, pero también lo es que la película de Oñate se había concebido como un entretenimiento entre amigos y no había sido exhibida ante el público, por lo que se suele considerar Una aventura vulgar, no solo presentada con gran éxito ante el público sino premiada en un concurso de ámbito nacional, la película inaugural del movimiento amateur en Murcia. Véase Cerón, 1991: 61-72.

6 Estudios específicos destacados sobre esta técnica de animación: Harryhausen, 2008; Purves, 2011.

7 Una dura crítica a la película de Oñate y, en general, a todas -con la única excepción de Esmaltes, de Juan Capdevila- cuantas fueron exhibidas y premiadas en dicho concurso, poniendo un especial énfasis negativo en las de animación de objetos, entre las que había obras de Mestres o Sagués, se da en Felíu, 1957b: 1-4. 
personajes -simples conos que parecen remitir a los capirotes de los penitentes- se mueven a un ritmo frenético por un sombrío e inhóspito paisaje, convincentemente logrado a partir de una maqueta realizada ex profeso para el proyecto. La música elegida es la correspondiente a la célebre composición de Mussorgsky Noche en el monte pelado, utilizada también por Disney en el penúltimo fragmento de su obra maestra Fantasia (Fantasía, 1940), así como por el ruso Alexandre Alexeiéff, en 1933, en un cortometraje experimental titulado como la pieza musical, en el que se empleó la técnica de animación de pantalla de agujas.

Aunque no fuese para realizar una película en su totalidad, se siguió empleando el stop motion en algunos planos de otras destacadas creaciones de la época, caso de Lectura clandestina (1961), en la que Juan Antonio Molina insufló vida a unos siniestros guantes, o de $E l$ domador (1962), filme de Vicente Massotti en el que un billete de mil pesetas se movía al silbido de su amo. Pero en aquellos primeros años de la década de los sesenta fue Pedro Sánchez Borreguero quien con El ahorcado $(1963)^{8}$ volvería a proponer como únicos protagonistas de la historia a unos objetos animados -se trataba en este caso de las fichas de un dominó-, como ya hiciera Oñate seis años antes con Póker. La película de Sánchez Borreguero iguala a la de su predecesor en consecución técnica, sumándole un sencillo pero sobresaliente argumento: el seis doble es "ahorcado", como se suele decir en el argot propio del juego, siendo finalmente portado por el resto de fichas en un curioso cortejo fúnebre.

No obstante, tuvo que llegar la década de los setenta -y más concretamente su segunda mitad- para que un realizador murciano dedicase su obra, prácticamente en exclusiva, a la animación de objetos. Hablamos de Francisco Hernández Egea, destacado integrante de la segunda generación de cineastas amateurs murcianos, quien formó, junto a Florentina Cánovas, Hercanfilms, marca bajo la cual realizaron decenas de cortometrajes. Salvo alguno de carácter documental -es el caso de Pinceles murcianos (1982), centrado en los principales pintores de la época-, sus filmes eran argumentales, recreando sencillas historias protagonizadas por los más inverosímiles personajes: un payaso de trapo y lana, unas figuritas de belén, un muñeco de madera, unos curiosos seres de plastilina, un plátano, una manzana, un mendrugo de pan, una chocolatina... Todos ellos cobraban vida gracias a la imaginación, pericia y paciencia de sus laboriosos creadores. El stop motion volvía a ser la técnica utilizada. Una cámara de Super-8 y un sencillo equipo de iluminación fueron sus únicas herramientas técnicas, a lo que habría que sumar un variado repertorio artesanal destinado a crear las figuras y los escenarios oportunos. Con sus creaciones participaron en multitud de concursos, principalmente de ámbito nacional, llegando a obtener decenas de galardones.

En su extensa filmografía destacan títulos como Un paquete diferente (1976), Canción de cuna (1977), Fantasía de Navidad (1977), La merienda (1977), Silencio, se rueda (1977) o Sobremesa (1979). Pero merecen una mención especial los dos siguientes: Una pequeña familia (1979) y Floren (1980). El primero de ellos es un sencillo pero completo documental sobre su propia forma de hacer las películas de animación de objetos. En él, mostrando todo lujo de detalles, se centra la atención en la confección de figuras y maquetas, señalando con precisión los diversos materiales y herramientas que empleaban para tal fin. Sin embargo, cuestiones puramente técnicas, caso de la iluminación o de la propia esencia del stop motion, son tratadas con menor detalle, lo que no impide que el espectador se haga una idea muy aproximada de las mismas. Por su parte, Floren es un delicado filme en el que la labor artística de un escultor -en este caso se trata del artista local Diego Mirete- se convierte en la auténtica protagonista. El artista se dispone a modelar en barro el retrato de una mujer -se trata de la propia Florentina Cánovas-, pero el material cobra vida como por arte de magia, realizándose la mayor parte de la obra sin mediación de mano o herramienta alguna. El resultado es fascinante, conseguido gracias a un stop motion perfectamente ejecutado. De hecho, resulta imposible al ver esta obra que no nos vengan a la memoria algunos de los trabajos más sobresalientes del checo Jan Švankmajer, sobre todo su famoso Možnosti dialogu (Dimensiones/posibilidades de diálogo, 1982)9.

8 Ese mismo año Antonio Pérez Bas también realizó Luna de trapo y Twist luminoso, igualmente protagonizadas por objetos animados, pero hoy desaparecidas.

9 Es cierto que el carácter simbólico y la intención de este y otros filmes del cineasta checo nada tienen que ver con lo pretendido en su cortometraje por el realizador murciano, siendo el esmerado uso del stop motion sobre las cabezas de arcilla su único, aunque notable, punto de conexión. 


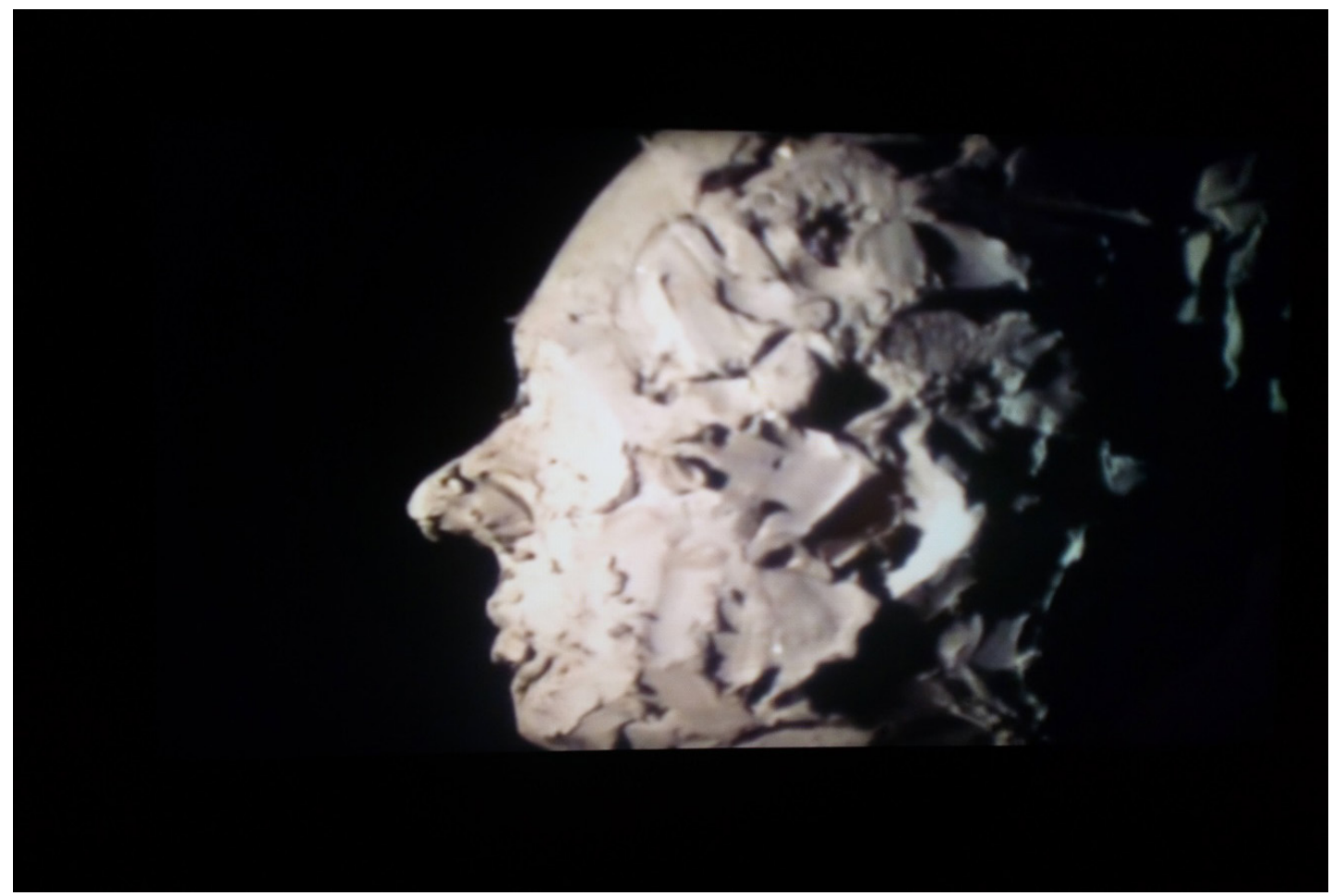

Figura 1. Floren (F. Hernández Egea y F. Cánovas, 1980)

En aquella misma década también destacan algunos filmes de animación realizados por Agustín Sánchez. Especial mención merece el titulado Plax y Plox (1976), pues resultó su principal aportación en el terreno de la animación de objetos. Se trata de una divertida historia protagonizada por dos cómicos muñecos de plastilina. Dicha producción obtuvo, además de numerosos premios a nivel nacional, el Trofeo de Bronce en el Festival de UNICA, celebrado en Maastricht en 1977.

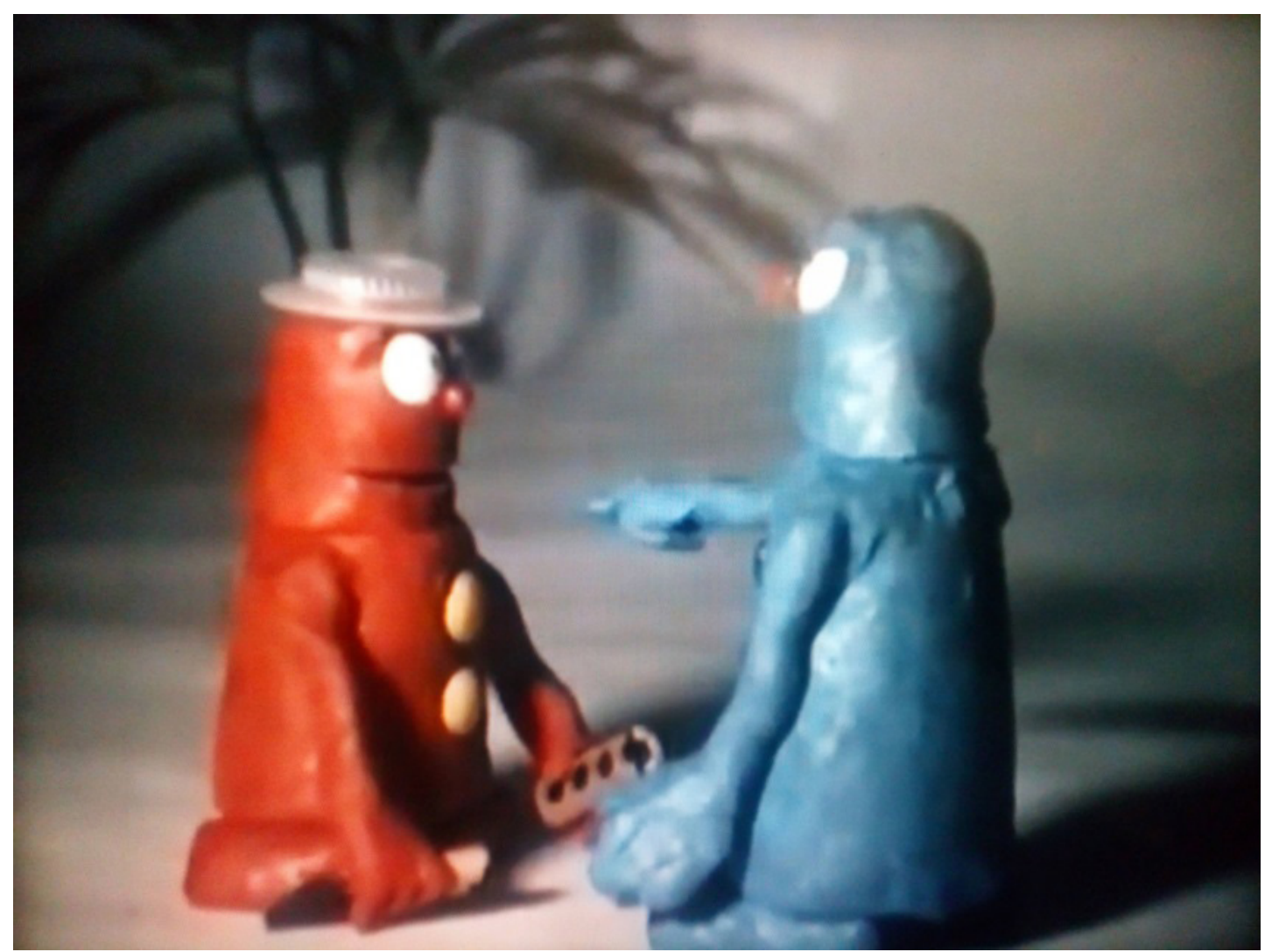

Figura 2. Plax y Plox (A. Sánchez, 1976) 


\section{ANIMACIÓN DE FORMAS}

Es cierto que la animación experimental basada en la abstracción vivió en los años cuarenta y cincuenta una época de esplendor. En dicho periodo, el principal artífice fue el escocés Norman McLaren, quien trabajaba en Montreal para la National Film Board of Canada desde 1941. Pero no es menos cierto que este tipo de animación hunde sus raíces unos años atrás, concretamente en el llamado cine abstracto que algunos artistas de vanguardia realizaron en la primera mitad de la década de los veinte. Hans Richter, Walter Ruttmann y Viking Eggeling destacaron entre ellos, poniendo las bases de lo que en los años treinta supondría un definitivo paso hacia la madurez de este tipo de creaciones -ya sonoras, lo que resulta un dato fundamental en filmes de estas características- de la mano de autores como Oskar Fischinger, Len Lye o el propio McLaren, quien daba entonces sus primeros pasos creativos.

Fue el prolífico e inquieto Antonio Medina el único en abordar este tipo de animación en Murcia. Los cineistas barceloneses serían también aquí un referente directo, volviendo a destacar Felipe Sagués y José Mestres -ya en los sesenta se añadirían otros catalanes con importantes aportaciones, caso de Joaquín Puigvert o Antonio Sirera-. De Medina hemos de mencionar Pinceles locos (1956), Fantasía en el puerto (1958) e Impresiones (1961), audaces películas en las que el movimiento de formas abstractas en íntima comunión con el acompañamiento musical supone su mayor mérito y atractivo. Pinceles locos se abre con unas imágenes realizadas, una vez más, con la técnica del stop motion. En pantalla aparecen unos pinceles que se mueven solos, a gran velocidad, pintando coloridas líneas sobre una superficie en blanco. Pero enseguida el tipo de animación cambia de lo figurativo a lo meramente abstracto, y del stop motion a una combinación de técnicas destinadas a animar diferentes formas planas. El ritmo frenético de dichas formas se armoniza a la perfección con la música escogida: la canción Rock-A-Beatin'Boggie de Bill Haley, interpretada por el grupo The Deep River Boys. La película obtuvo varios premios, tanto en concursos en el extranjero -Carcasona- como nacionales -Barcelona ${ }^{10}$, León, Cáceres...--.

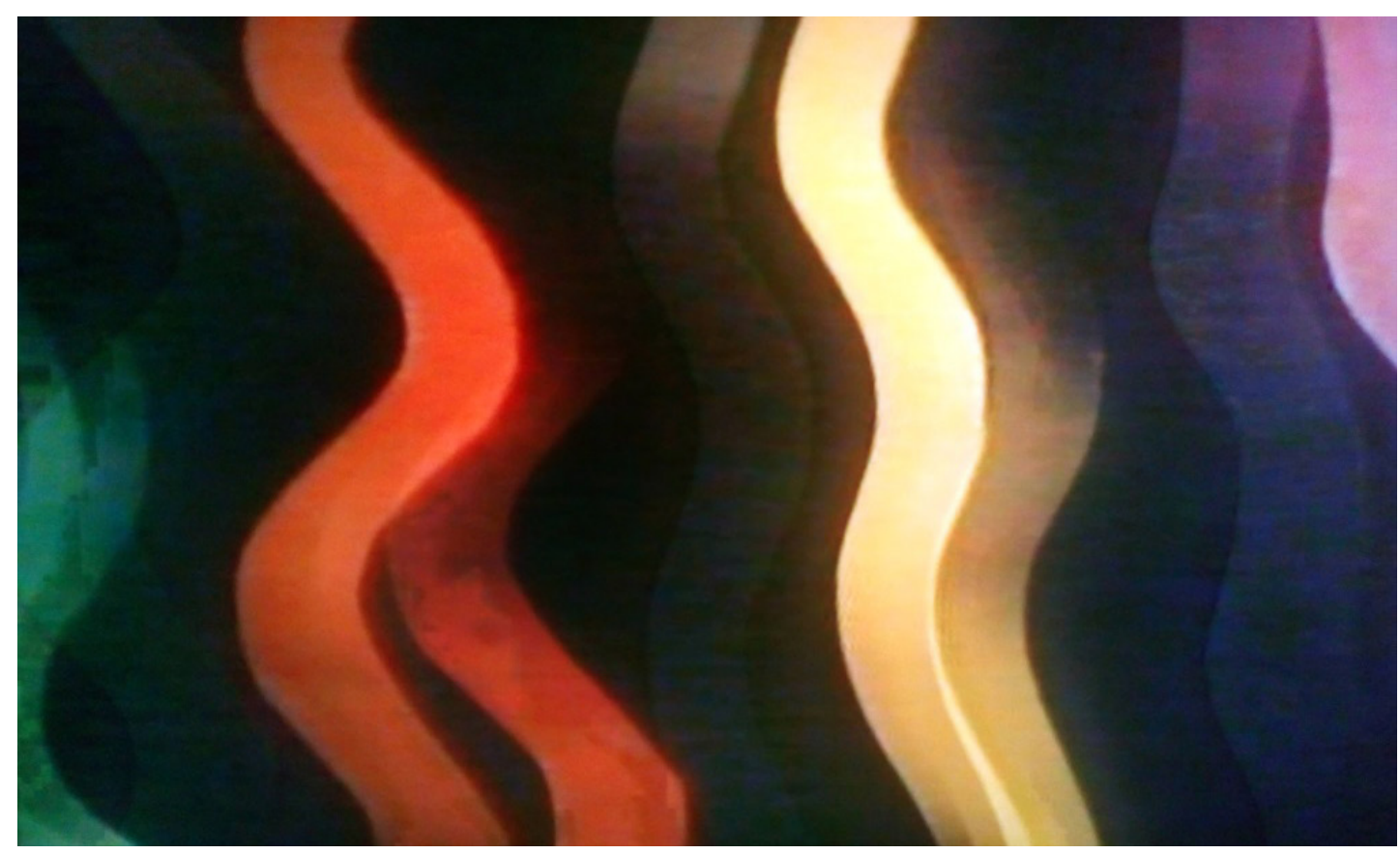

Figura 3. Pinceles locos (A. Medina, 1956)

A menudo se ha querido ver la influencia de las creaciones experimentales de Norman McLaren ${ }^{11}$ en este filme de Medina. En este sentido, si analizamos con detenimiento las películas del cineasta escocés apreciaremos que, más que los filmes con ciertos elementos

10 Pese a todo, tampoco se libró de la feroz crítica que se le dedicó a las obras premiadas aquel año desde la revista Inquietud. Véase Felíu, 1957b: 3.

11 Sobre la ingente y novedosa obra de este cineasta experimental destacan publicaciones como: McWilliams, 1991; Richard, 1982. 
figurativos -Love on the Wing (1938), Dollar Dance (1943)...- o la abstracción de cierta inspiración mironiana de manchas y formas con vida propia -Dots (1940), Boogie-Doodle (1940)...-, fue otro tipo de animación de formas múltiples y repetitivas, a menudo trabajadas sobre el propio soporte fílmico -Fiddle-De-Dee (1947), Begone Dull Care (1949)...-, el que pudo influir de una manera más directa en el cineísta murciano. De la misma manera que lo pudieron haber hecho otros trabajos similares de los años treinta, realizados por los principales predecesores de McLaren, los ya mencionados Oskar Fischinger y Len Lye. Aunque, como ya se ha dicho anteriormente, serían los cineistas barceloneses sus referentes más directos, destacando una vez más Mestres con filmes como Nocturno (1955) o Forma, color y ritmo (1956).

Fantasía en el puerto también obtuvo un notable éxito, siendo merecedora de diversos galardones, no solo en Murcia o Barcelona, sino también en el Festival Internacional de Montecatini y en el de UNICA, celebrado en Helsinki en 1959. Pero lo primero que hay que aclarar respecto a este singular filme es que no se trata, en sentido estricto, de una película de animación ${ }^{12}$. Y es que Medina no tuvo en esta ocasión que dibujar ni animar forma ni objeto alguno, pues Fantasía en el puerto no es más -ni tampoco menos- que unas imágenes filmadas, con la cámara invertida, de las trémulas aguas de un puerto, en las que se reflejan los mástiles de los barcos. El resultado es el de unas fascinantes formas abstractas en sinuoso movimiento. La música que las acompañaba en perfecta armonía pertenece, en este caso, al disco Hawaiian Memories, de Danny Stewart and His Islanders. Vuelven a resonar los ecos de las realizaciones de McLaren en esta obra, lo que no evita que goce de originalidad y entidad propia.

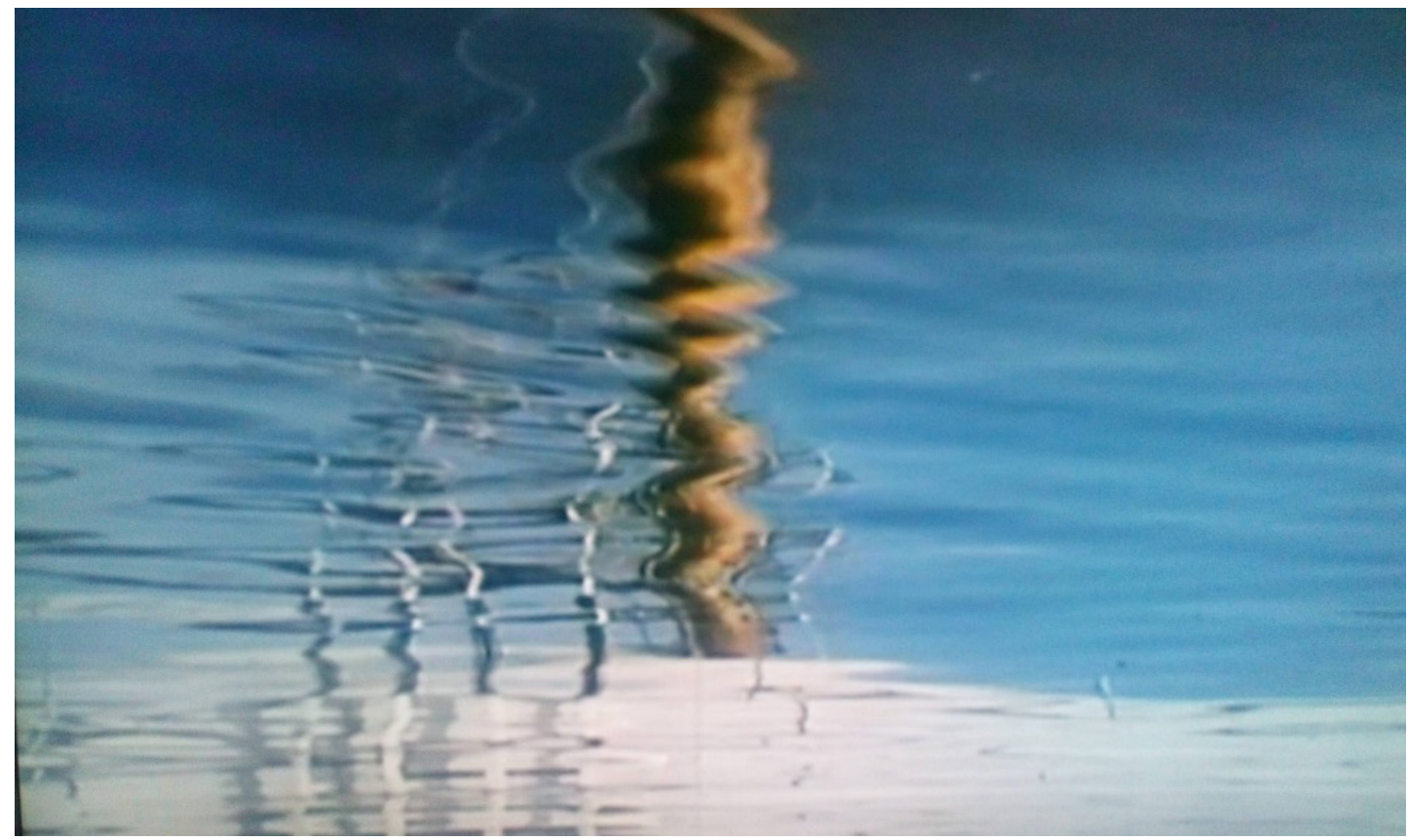

Figura 4. Fantasía en el puerto (A. Medina, 1958)

Impresiones fue su última realización decididamente experimental. Se trata de una película en blanco y negro en la que una serie de imágenes de troncos y ramas desnudas sirven como fondo a las formas abstractas que danzan al ritmo de la música, en esta ocasión una pieza de jazz. Dichas formas fueron realizadas rayando y pintando sobre el propio soporte fílmico. Una vez más, los filmes de Norman McLaren y Len Lye, sobre todo aquellos en los que actuaban directamente sobre el celuloide, parecen ser los principales referentes para el realizador murciano.

12 Algo similar sucede con otro curioso filme del autor, El muelle (1974), en el que realmente no existe una animación tal cual, aunque el efecto final sea el de unas formas abstractas en movimiento, logrado al colocar la cámara en el interior de un muelle. 


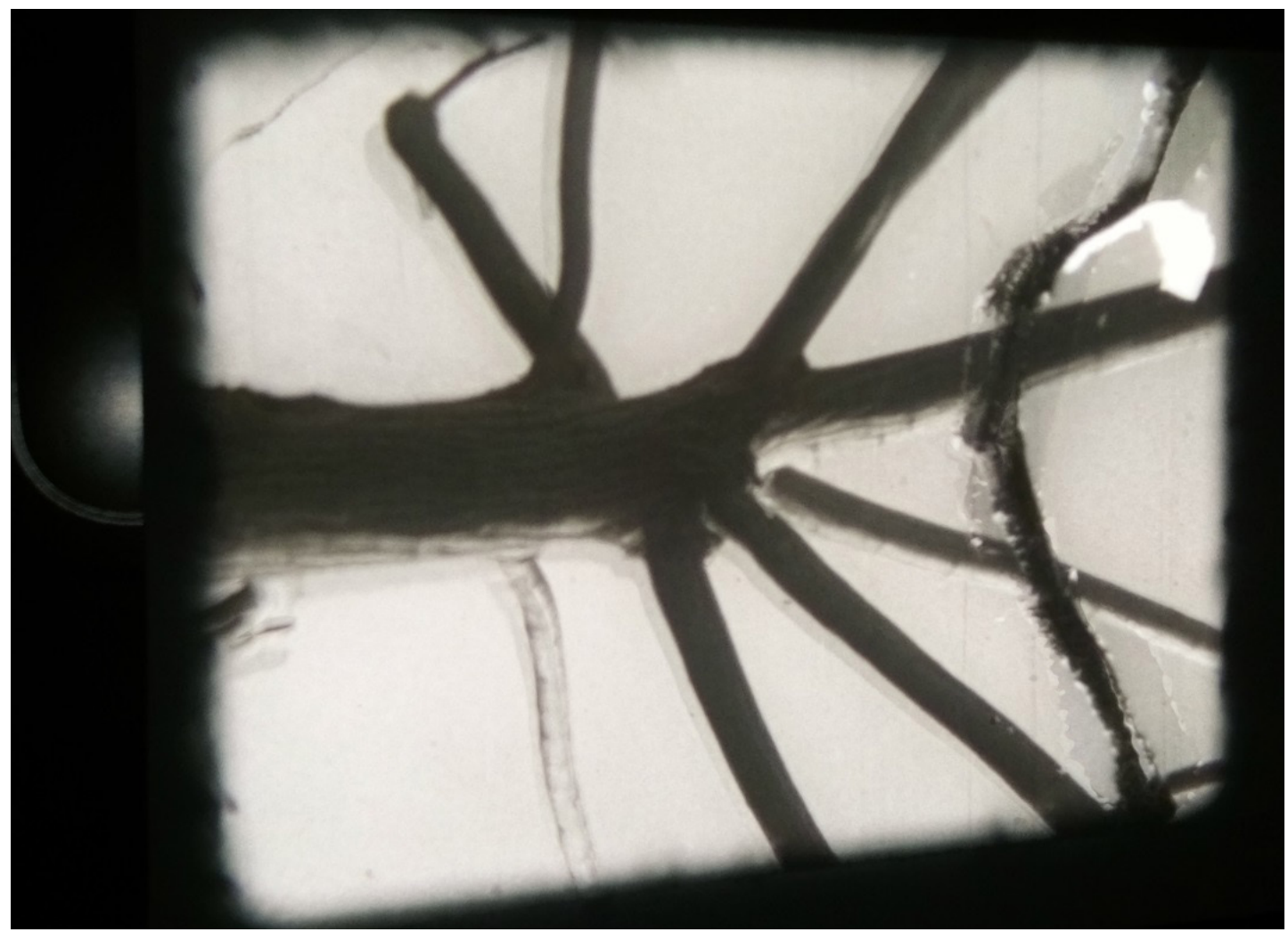

Figura 5. Impresiones (A. Medina, 1961)

De manera que estas tres películas se convierten en las creaciones del autor que mejor unen y condensan sus dos principales pasiones artísticas: el cine y la pintura. Porque Antonio Medina Bardón, además de ser el cineista con mayor número de realizaciones, también fue pintor, fundamentalmente acuarelista. En definitiva, en lo que al cine se refiere, destacó al tocar todos los temas, géneros y técnicas, de la misma manera que demostró una inusual versatilidad en lo que a las labores relacionadas con el arte cinematográfico se refiere, llegando a ser, según la ocasión, productor, director, operador, guionista o actor. Es decir, un prodigio de creatividad, sin cuya figura resultaría del todo imposible entender lo que fue el cine amateur murciano en aquellos años de esplendor.

\section{CONCLUSIONES}

Tras este acercamiento a lo que supusieron, dentro de ese amplio campo creativo que es la animación, los filmes de formas abstractas y objetos animados dentro del movimiento de cine amateur desarrollado en Murcia entre los años cincuenta y setenta, se pueden extraer las siguientes conclusiones. En primer lugar, resultaría digno de subrayarse el hecho de que en aquellas tres décadas, los realizadores murcianos que se interesaron por la animación no lo hicieran, en concreto, por los dibujos animados, sino por otras técnicas que solían obtener como resultados creaciones, por lo general, destinadas a un público adulto o, al menos, no exclusivamente infantil. Habría que esperar a finales de los setenta para que los dibujos animados tuviesen continuidad en la obra de un autor murciano, siendo este José María Candel, todavía activo. En segundo lugar hemos de destacar el mayor número de películas de animación de objetos en relación a las de formas abstractas. De hecho, estos filmes realizados con la técnica del stop-motion se dieron durante las tres décadas en las que se centra el presente estudio, siendo creaciones de diversos autores. Por el contrario, la animación de formas fue cultivada en aquellos años por un solo cineasta, Medina Bardón, quien demostró estar al corriente de esa animación experimental desarrollada fundamentalmente por McLaren, a nivel internacional, y por los catalanes Sagués y Mestres, a nivel nacional. En definitiva, se puede observar cómo ese carácter más decididamente experimental solo centró la atención de un realizador especialmente prolífico y versátil como lo fue Medina, siendo la preferencia mayoritaria la de la animación de objetos en películas generalmente narrativas y de temáticas amables. 


\section{BIBLIOGRAFÍA}

- Artigas, J. (2002). Cine de animación experimental en España. Cervantes Virtual: http:// www.cervantesvirtual.com/obra-visor/cine-de-animacion-experimental-en-espana--0/ html/ff8fdde6-82b1-11df-acc7-002185ce6064_7.html

- Bierton, T. (2004). Stop-Motion Puppet Sculpting: A Manual of Foam Injection, Build-Up and Finishing Techniques. USA: McFarland \& Co Inc Pub.

- Bonet, E. y Palacio, M. (1983) Práctica fílmica y vanguardia artística en España, 1925-1981. Madrid: Universidad Complutense.

- Cánovas, J.T. y Cerón, J. F. (1990), Murcianos en el cine. Murcia: Cajamurcia Obra Cultural.

- Cerón, J. F. (ed.) (2003a): Encuadre. Tomo I. Estudios e indices. 50 Aniversario de Una aventura vulgar. Murcia: Universidad de Murcia-Aula de Cine.

- Cerón, J. F. (ed.) (2003b): Encuadre. Tomo II. Edición Facsímil. Murcia: Universidad de Murcia-Aula de Cine.

- Cerón Gómez, J. F. (2002). El cine amateur en Murcia durante la década de los años cincuenta. En Ruiz Rojo, J. A. (coordinador), En torno al cine aficionado. Guadalajara: Diputación Provincial de Guadalajara, CEFIHGU, 49-64.

- Cerón Gómez, J. F. (1991). Los inicios del cine amateur en Murcia, Imafronte (6-7), 61-72.

- De la Rosa, E. (1996). El cortometraje de animación. En VV.AA. Historia del cortometraje español. Madrid: Festival de Cine de Alcalá de Henares, 387-465.

- Díaz Maroto, C. (2010). Ray Harryhausen. El mago del stop-motion. Madrid: Calamar Ediciones.

- Felíu, J. (1957a). ¿Por qué... Inquietud, 8, 14-15.

- Felíu, J. (1957b). El cine amateur del concurso de 1957. Inquietud, 10, 1-4.

- Gubern, R. (1999). Proyector de luna. La Generación del 27 y el cine. Barcelona: Anagrama.

- Harryhausen, Ray. (2008). A Century of Model Animation. London: Aurum Press Ltd.

- McWilliams, D. (1991). Norman McLaren on the Creative Process. Montreal: NFB.

- Palacio, M. (1997). Cine de vanguardia. En VV. AA. Historia general del cine. Vol. V. Europa y Asia (1918-1939). Madrid: Cátedra, 259-302.

- Purves, B. (2011). Stop motion. Barcelona: Blume.

- Ramallo Asensio, G. (coord.). (2018). Homenaje a los cineastas amateurs murcianos y la Filmoteca Regional de Murcia. Murcia: Asociación Patrimonio Siglo XXI.

- Richard, V. T. (1982). Norman McLaren, Manipulator of Movement: The National Film Board Years, 1947-67. London-Toronto: University of Delaware Press.

- Romaguera i Ramió, J. (1996). Esbozo de una historia del cine amateur español. En VV.AA. Historia del cortometraje español. Madrid: Festival de Cine de Alcalá de Henares, 337-375.

- Romaguera i Ramió, J. (1991). 30 años de experimentación en el cine amateur catalán. En VV.AA. Las vanguardias artísticas en la historia del cine español. Actas del III Congreso de la AEHC. San Sebastián: Filmoteca Vasca, 213-231.

- Sanz, J. B. (1990). Antonio Medina Bardón. En Cánovas, J. T. y Cerón , J. F., 184-186.

- Shaw, S. (2008). Stop Motion: Craft Skills for Model Animation. London: Taylor and Francis Ltd.

- Torrella, J. (1965). Crónica y análisis del cine amateur español. Madrid: Ediciones Rialp.

- VV.AA. (1996). Historia del cortometraje español. Madrid: Festival de Cine de Alcalá de Henares. 